\title{
Together or Separate in the Neighbourhood?: Contacts Between Natives and Turks in Amsterdam
}

\author{
Peer Smets* and Nicoline Kreuk
}

Department of Sociology, VU University Amsterdam, The Netherlands

\begin{abstract}
The integration of non-Western migrants and especially Muslims is an issue of hot public debate in the Netherlands. This debate has been largely dominated by stereotypical images of Muslims and natives, which only serve to reinforce 'we-they' configurations. However, one gets a rather different view if one looks at the daily encounters between natives and Turks in an ethnically mixed neighbourhood in Amsterdam. The interactions between natives and Turks have thus been examined to gain insight into the dynamics of the interethnic contacts. This study reveals that contact between native born and Turks, and mutual judgements are manifold. In particular, the examination of the everyday interaction between Turks and natives can enrich the debate on Turks (Muslims) and integration.
\end{abstract}

Keywords: Integration, interethnic contacts, established-outsiders, neighbourhood.

\section{INTRODUCTION}

Multiculturalism, as a model for an ethnically diversified society, has been practised in a variety of countries, such as the United Kingdom and Canada. Social scientists [1-4] often tend to assume that the Netherlands has employed a model of multiculturalism, which offers minorities the chance to achieve a better life. However, Duyvendak et al. [5] contend that multicultural integration policies have never been practised in the Netherlands for various reasons. Integration policies have not been well planned instead only ad hoc decisions are made. Moreover, the Dutch system of compartmentalisation is largely responsible for the segregation of migrants, most particularly Muslims. In this system, all groups have been compartmentalised along socio-political and religious lines and have consequently gained governmental support to establish separate institutions, such as schools, broadcasting and welfare organisations. This is often referred to as 'pillarisation'. At this level, integration has successfully taken place within the confines of a 'pillar', where individuals belonging to the same ethnic group can express their identity more easily [6].

Although the multicultural status of the Netherlands is debatable, the stability of an ethnically-pluriform society in the Netherlands is certainly under threat. There are concerns about issues, such as the allegedly deteriorating bonds between citizens, fading norms and values, weakening social control and the accentuation of interethnic cleavages. In the cities of Amsterdam, Rotterdam, The Hague and Utrecht, many people are thought to live separate lives, which are invisible to their neighbours. There are also anxieties about the attitudes and contacts between natives and especially Muslim migrants. In this regard, Duyvendak et al. [5] remark:

*Address correspondence to this author at the Department of Sociology, VU University Amsterdam, De Boelelaan 1081, 1081 HV Amsterdam, The Netherlands; Email: pgsm.smets@fsw.vu.nl

\begin{abstract}
'Cultural difference or separateness plays a problematic role in the integration process of migrants $(\ldots)$ the majority population is coming to see the cultural difference as [sic] more in terms of a problem, which, for instance, does little to enhance the openness of Dutch institutions to migrants.' (p. 11)
\end{abstract}

The majority of Dutch natives - both well and lesseducated citizens - use their widely shared progressive values with respect to, for example, freedom of speech, families, sexuality and gender roles, to stigmatise and exclude Muslim migrants. These migrants are regarded as a threat to these values [5].

Being unfamiliar with one's neighbours can lead to anxieties within a neighbourhood. Such anxieties have not only been intensified by the assassinations of the politician Pim Fortuyn in 2002 and the film director Theo van Gogh in 2004, but also by episodes elsewhere in the world, such as the September $11^{\text {th }}$ attacks on the Twin Towers in New York in 2001. These attacks, often referred to as 9-11 were a series of coordinated suicide attacks with airliners upon the United States by al-Qaeda. These attacks had major ramifications around the world, with the US declaring a war on terrorism in response. After this, bombings also took place in Spain, London and elsewhere. These threats of terrorism have increased tensions between Muslims and non-Muslims.

At the political level, Muslim migrants tend to be blamed for being unwilling to integrate into Dutch society. Moreover, Geert Wilders, a member of the Dutch parliament, has been an outspoken and harsh critic of Islam. Such incidents have resulted in an increasingly widening gap also between Muslims and natives in the Netherlands [4, 7]. However, a certain number of basic shared values are needed to create social unity, but this is still insufficient.

The discourse on integration tends to undervalue everyday relationships between people. This study seeks to fill this gap in knowledge by exploring the dynamics of daily encounters between Turks and natives in an ethnically-mixed 
neighbourhood in Amsterdam. The central question addressed in this study is: how can the similarities and differences between the intra-ethnic and interethnic contacts between Turks and natives in two neighbourhoods (4 and 5) in the Slotermeer district in Amsterdam be explained?

\section{NEIGHBOURHOOD CONTACTS IN THEORETICAL PERSPECTIVE}

Neighbourhood contacts have specific characteristics. Firstly, almost every urbanite has neighbours, but not everyone has a partner, friends, colleagues or family. Secondly, relationships with neighbours are usually a matter of free choice. Thirdly, neighbours know things about each other, not because they necessarily talk to each other, but because they live next door or nearby. Finally, the tenor of neighbourhood contacts can by no means be determined in advance [8].

Blokland [9] identifies neighbourhood residents who participate in a segregated, encapsulated, isolated and integrated network. Firstly, a segregated network, which consists of a number of separate clusters, encompasses different people to meet different needs. For example, people will go to bars with some acquaintances, while they play pool with others. Secondly, people in an encapsulated network have the tightest relations. They are among peers, where a tight relationship may develop, such as friendship or acquaintanceship. Thirdly, neighbourhood residents in an isolated network, which is small and with a low density, have a very small number of contacts. These contacts are hardly ever useful in other situations. Fourthly, an integrated network encompasses a mixture of encapsulated and segregated networks. However, relations 'are more extensive and less close-knit than those of the encapsulated, but not as widely dispersed and specialized as those of the segregated were.' (p. 57). This diversity offers them active as well as potential social relations, including different kinds of social support.

Neighbourhood contacts can be separated into intra- and interethnic contacts. Here, ethnicity and religion can determine the feeling of belonging to a certain (peer) group, the formation of one's social identity and distinctions made between the in-group and out-group. When people do not belong to the same peer group, as often occurs between people of different ethnic backgrounds, tensions may arise. The natural response to misunderstandings and incomprehension caused by ethnic differences is the avoidance or severing of contact, even when it concerns greeting only. An important condition for improving mutual contact and communication between groups or individuals is an attitude of openness, curiosity and self-awareness [10]. Moreover, positive knowledge about the other is also of great importance and can lead to the development of affective bonds [11]. Such knowledge is also important for enabling the development of trust relations, which are important for establishing and maintaining contacts and are even indispensable for friendships [12]. Trust is often dependent on reciprocity; reciprocal exchange connects people through feelings of gratitude and obligation. It is sometimes even regarded as the moral cement of society [12-14].

In short, the most important preconditions to avoid tensions are: an open attitude, knowledge about the other and reciprocal trust relations. This is not common, especially when ethnic, religious or cultural differences play an important role. This can be linked with the 'established' and 'outsiders' configurations of Elias and Scotson [15]. Their study from the 1960s offers an insight into explanations for tension and prejudice between two groups of residents in an English working-class neighbourhood. The old core residents stigmatise the new residents as maladjusted and inferior in such a way that the new residents develop a feeling of inferiority. The established form a closed group, who identify strongly with each other and assume themselves to be better people than the outsiders. The superiority of the established is mainly due to their longstanding mutual ties, which are accompanied by collective identification and mutually shared norms. Gossip acts as an important mechanism to exclude outsiders and strengthened social cohesion among the established. Social cohesion among the outsiders is weakly developed, which places them in a far weaker position [15].

Elias and Scotson [15] highlight the fact that newcomers can be seen as intruders. Ethnicity, however, plays no role whatsoever in their research. When 'established' and 'outsiders' are ethnically different, new insights can be gained. In their study of a neighbourhood in the Dutch city of Utrecht, Bovenkerk et al. [16] contended that, instead of excluding their new neighbours, the established natives were actually engaged in concerted attempts to involve the new non-western migrants. These natives primarily wanted their new Turkish and Moroccan neighbours to adjust to Dutch habits and norms. However, when the number of nonWestern migrants increased, the non-Western migrants tended to withdraw into their own groups. This leads to reprisals by the natives against the newcomers. The natives want the newcomers to adjust to established values with respect to tidiness, orderliness and decency: keeping the neighbourhood neat, making children go to bed early and speaking the Dutch language [16]. Likewise, Blokland [9] also suggests that the natives in a Rotterdam neighbourhood do not exclude non-Western migrants. Nonetheless, they are not considered equals; they are simply embraced to be 'made' equal and are expected to adjust to Dutch norms and values.

In his study of a German neighbourhood, May [17] found that Turkish migrants were no longer confined to the position of powerless outsiders. Natives noticed and feared an increasing cohesion between Turks and a growing control over material resources, but in reality cohesion among natives weakened over the course of time. May claims that status and power differences, influenced by broader society, public discourse, the media and relations with the rest of the city and nation, shape the established-outsiders configuration at the neighbourhood level. This contradicts Elias and Scotson's notion that a neighbourhood could be studied as an isolated place.

The concept social identity can be used to explore the coexistence of various ethnic groups and their attitudes with respect to their own and the other groups. This concept links the individual and group level for it implies that an identity is to a large extent formed by the groups to which one belongs. Miller and Brewer [18] demonstrate that social identities are always 'part' identities: people belong to multiple social groups. For example, Turks can simultaneously be parents, teachers, Muslims and Dutch people [19, 20]. 
Social identification encompasses the relationship between identification and attitude towards one's own as well as other groups, which can lead a certain degree of social competition resulting in prejudice, discrimination and social exclusion. In general, people judge their own group positively and negatively in relation to those whom they feel they do not belong [19] Nowadays, non-Western migrants are assumed to focus more on Dutch society and cultural habits and less on their own ethnic group. The political and public debate on the integration of non-western migrants has become far harsher. Simultaneously, Turks and natives employ a stronger orientation towards their own social group [19, 20].

Apart from a reinforced orientation toward their own ethnic group, the importance of religious identity amongst Turks is believed to have increased. Almost all Turks in the Netherlands (about 96\%) are Muslim. Turks tend to emphasise their religious differences with respect to natives more than their ethnic identity [21-22]. Moreover, in the public and political debates, the label 'Turk' and 'Muslim' are often used synonymously. This results in a greater visibility of Islamic practises in secularised Dutch society [23]. Verkuyten [19] argues that Turks in the Netherlands tend to think more positively about Muslims and are generally negatively inclined toward Jews and the irreligious. Their attitude towards Dutch natives or other ethnic groups is often neutral. He explains this by the fact that Turks consider themselves not only as Muslim, but also as Dutch.

Since social identity can create a sense of belonging or not-belonging to a group, the competition and contact hypotheses come into play. Both hypotheses make an opposing prediction about the cohabitation of or clashes between multiple ethnic groups. The competition hypothesis suggests that the presence of a large minority population among a majority of natives will lead to feelings of being under threat, thus resulting in prejudice. Although a large part of the threat is possibly economic or political, it can also be cultural or social. Central to the competition hypothesis is the idea that ethnic groups have opposing interests when competing to acquire scarce goods, such as jobs, housing and social benefits. Consequently, competition will arise between the groups, which is often experienced as threatening [11].

Many research studies, according to Gijsberts and Dagevos [24], confirm that negative attitudes with respect to minorities are often found among the less privileged groups in society. Since non-Western migrants often find themselves in the lower social positions, natives in this same social position experience the greatest degree of competition and will therefore feel the most threatened. In their later work, Gijsberts and Dagevos [25] have found indications that the competition hypothesis on the neighbourhood level applies when natives constitute less than fifty percent of the population. Under such circumstances, natives can feel threatened by the large migrant population.

In contrast, the contact hypothesis does not presume that the presence of a large minority population among natives is problematic, but assumes that contact between ethnic groups will lead to mutual understanding. Consequently, mutual negative attitudes will diminish. In short, the contact hypothesis can be explained by the adage: 'to be known is to be loved' $[24,25]$.
Turks are the most segregated ethnic group in the Netherlands. They live concentrated in specific low-income neighbourhoods in the large cities. This segregation negatively influences the opportunities to meet and therefore also restricts the contact that the group has with natives [26]. The fact that Turks are the most segregated ethnic group and thus probably have less contact with natives will, according to the contact hypothesis, have a negative impact on the mutual assessment of natives and Turks. More contact between Turks and natives will possibly improve the quality of their interethnic relations.

Bovenkerk et al. [16] question the contact hypothesis' assumption that living in an ethnically-mixed neighbourhood will improve understanding between separate groups. They have found, for example, that the Turkish neighbour is often accepted, but that Turks as a group are judged more unfavourably. The 'good' Turkish neighbour is often seen as an exception.

Allport [27], who first formulated the contact hypothesis, assumed that the effects of contact on prejudice depend, for example, on the quality of the contact, whether it is voluntary, if it exists between people of an equal status and is established in a cooperative environment [11]. Other researchers have since added numerous other conditions to this list. This has led to a multiplicity of 'favourable' and 'unfavourable' conditions $[11,28]$. However, these numerous conditions for enabling optimal contact make the hypothesis unfalsifiable [11]. Despite these shortcomings, the contact hypothesis offers the possibility of studying mutual contacts in specific contexts. Here it will provide insight into the dynamics of the daily encounters between natives and Turks in two neighbourhoods of Amsterdam.

\section{GEUZENVELD-SLOTERMEER, AMSTERDAM NEW WEST}

The district Slotermeer, established in 1952, is a subdivision of the urban district Geuzenveld-Slotermeer and Amsterdam New West. Slotermeer is divided into five neighbourhoods. This research was conducted in neighbourhoods 4 and 5 (see Fig. 1). Neighbourhood 4 is one of the smallest neighbourhoods with just 2,833 inhabitants, while neighbourhood 5 is relatively large with 7,652 people living there (see Table 1).

Table 1. Number of Inhabitants of the District GeuzenveldSlotermeer and the Research Neighbourhoods, 2006 $[29,30]$

\begin{tabular}{|c|c|}
\hline District Geuzenveld-Slotermeer & 41,000 \\
\hline Neighbourhood 4 & 2,833 \\
\hline Neighbourhood 5 & 7,652 \\
\hline
\end{tabular}

Although neighbourhoods 4 and 5 are administratively divided, residents of both neighbourhoods share facilities, such as elementary schools and shops. Neighbourhoods 4 and 5 border upon each other and are separated from the surrounding neighbourhoods by a park and broad roads. The housing stock consists mainly of cheap social rental housing and is a mixture of houses including high- and middle-rise flats. Social rental housing represents about $80 \%$ of the total 


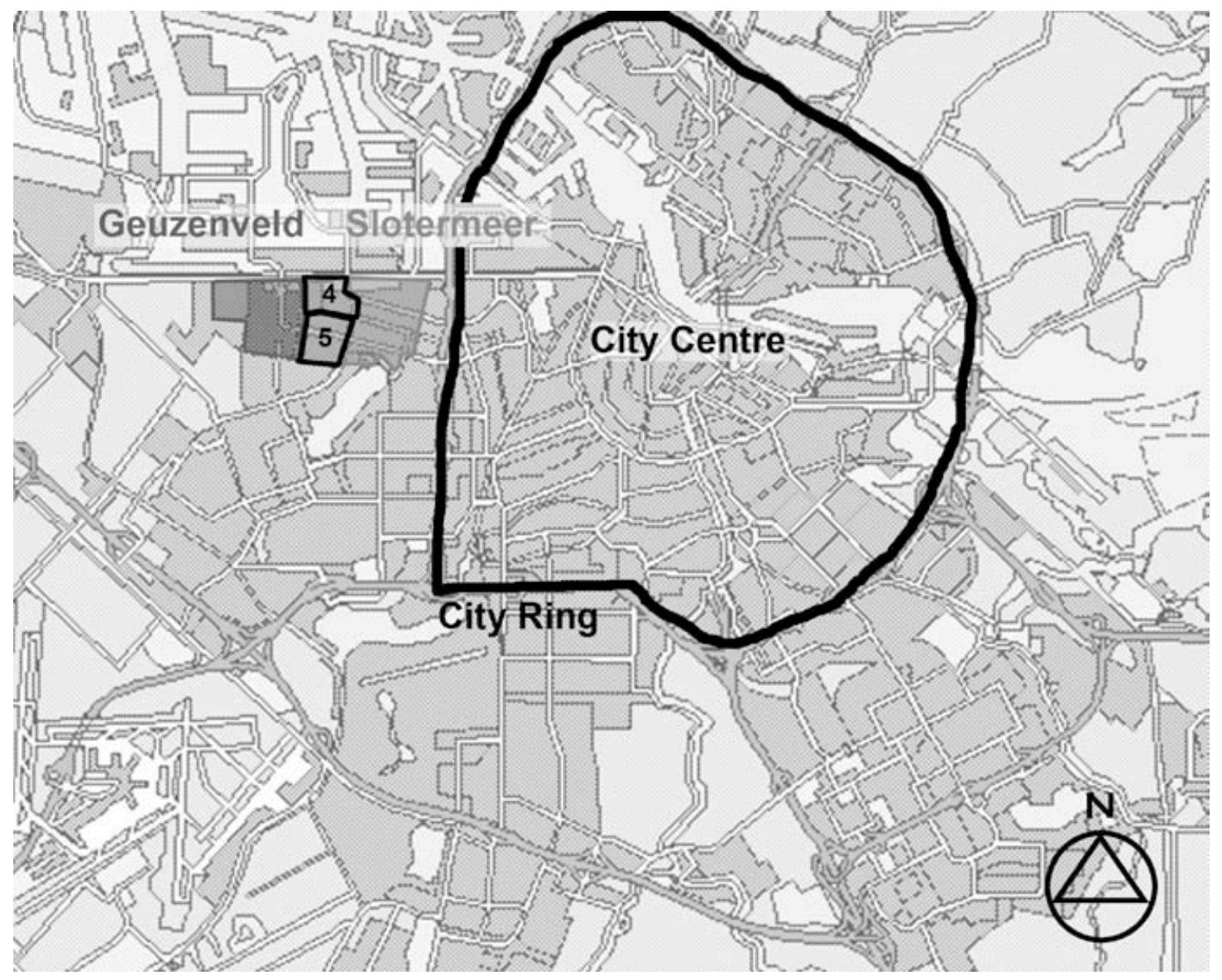

Fig. (1). Amsterdam and the research neighbourhoods 4 and 5 in district Geuzenveld-Slotermeer [31].

housing stock [30]. Some of the housing units are very small and have only two rooms. However, the largest proportion of the houses, have 3 to 4 rooms. Apart from these, there are also some larger houses with 5, 6 or even 7 rooms, but these are few and far between. Part of the existing house supply remains empty, having been earmarked for renovation or demolition.

In comparison to Amsterdam in general, the urban district is a relatively poor area. This is reflected in a lower average income, and a higher rate of unemployment and a greater number of social benefit claimants. Moreover, more non-Western migrants live in this urban district and fewer natives and Western migrants (see Table 2).

Table 2. Population Compositions of Amsterdam, the District Geuzenveld-Slotermeer and Neighbourhoods 4 and 5 in $\%, 2006[29,30]$

\begin{tabular}{|l|c|c|c|}
\hline & Amsterdam & $\begin{array}{c}\text { Geuzenveld- } \\
\text { Slotermeer }\end{array}$ & $\begin{array}{c}\text { Neighbourhood } \\
\mathbf{4 , 5}\end{array}$ \\
\hline \hline Natives & 51.5 & 35.3 & 30.4 \\
\hline Western migrants & 20 & 8.9 & 7.8 \\
\hline $\begin{array}{l}\text { Non-Western } \\
\text { migrants }\end{array}$ & 34.3 & 55.8 & 61.8 \\
\hline Turks & 5.2 & 16.5 & 16.6 \\
\hline Moroccans & 8.8 & 23.8 & 28.5 \\
\hline
\end{tabular}

Neighbourhoods 4 and 5 have been categorised as 'problematic neighbourhoods' by the Ministry of VROM (Housing, Spatial Planning and Environment), which provides funding for the improvement of liveability and social cohesion. Moreover, a large restructuring operation in the entire district aims to establish a more densely populated area. The housing stock will thus be renovated or demolished. Moreover, owner-occupied housing is under construction in empty lots, which should attract more privileged residents.

The district has a bad reputation, which is also due to the fact that a native family, known as the 'Tokkies', gained a significant amount of media attention not only in the newspapers, but also on television in 2003 and 2004. These stories drew attention to violent feuds between this 'problematic' family and their neighbours. Since that time, the name 'Tokkies' has become an epithet for anti-social families. In order to 'socialise' such families they initially were relocated to neighbourhood 4. Meanwhile, some families have been expelled from the neighbourhood altogether as a result of nuisance and uncivil behaviour.

\section{METHODOLOGY}

In addition to participant observation, semi-structured interviews were held with 22 native and 15 Turkish residents. The snowball sampling method was used to recruit new respondents. The snowball sampling method entails each person interviewed being asked to suggest additional people for interviewing [32]. This method was found to be 
useful for recruiting native residents, but among Turkish interviewees it was difficult to employ. Many of the Turks interviewed were very hesitant to forward the names of other Turkish residents, because they did not know if these people would appreciate being identified. In other cases, interviewees believed that the language proficiency of their acquaintances or family would not be sufficient for an interview. Furthermore, some Turkish respondents simply did not know any other Turks in the neighbourhood well enough to pass on their names.

The interviews had a very informal character. They proceeded according to a checklist and consequently were not bound to a strict formulation or order of questions. The duration of the interviews was in most cases between one and two hours. During the interviews the probing technique [32] was used to encourage the respondents to elaborate on their answers. In most instances, neighbourhood residents were very willing to talk about the subject. The main sticking point was some of the Turkish interviewees' lack of proficiency in speaking the Dutch language. However, all respondents took the requisite time to talk to the interviewers, so some very interesting research material was successful gathered in the end.

Information about the neighbourhoods was gathered by interviewing key figures in the neighbourhoods who also helped to recruit native and Turkish residents. Information about current events and developments in the neighbourhoods were followed by reading district and neighbourhood papers. Gatherings, such as district meetings about the restructuring of the district and a multicultural women's festival, were visited.

The collected data were analysed according to the constant comparative method [33], which means that the data sampling and analysis are an integrated process. Analytical sessions were, therefore, regularly organised during the data collection period. After the data collection, the data were coded and labelled with respect to different concepts. The coded perceptions, visions and relevant information were described in a matrix, which made it possible to construct a typology of the interviewed residents. It appeared that this classification largely fits Blokland's distinction of networks.

\section{INTRA-ETHNIC CONTACTS OF NATIVES}

Many natives, especially those over 55, were familiar with their fellow natives living in their block or street and its direct surroundings. Those who had lived in the neighbourhood for a long period appreciate the fact that they are able to recognise others in the street. However, this has diminished due the changing composition of the neighbourhood population. Elderly people in particular have seen their peers move to nursing homes. This has subsequently led to a spread of the remaining elderly people in the neighbourhood. Meanwhile, the number of non-Western migrants increased.

Although all respondents agreed that greeting others should be self-evident, this can be influenced by the weather. As Kees (49) illustrates: 'If the sun shines and you are cheerful you will greet everybody you want to. If it is raining, you are in a hurry and walk on the street differently.'

Eye contact, the first impressions of an unknown native and the situation at hand will influence whether people will greet one another. Natives tend to greet unfamiliar natives when they make a positive first impression. Apart from eye contact, some natives wave to each other in greeting or even engage in conversation. Chitchat is common between people who know or recognise each other, for example next door neighbours or those living in the same apartment block. Moreover, walking with a dog acts as catalyst for making contact and renders mutual recognition less important.

The topic of conversation can differ. An important question is 'Everything OK?' or 'How are you?'; this can elicit (often superficial) verbal interaction about health issues and events in the neighbourhood. The natives Tiny (85) and Carla (79) have lived on the same street for 53 years, they go shopping together and walk arm in arm in the local square. Although they discuss many issues, such as their shared resistance to the demolition and construction of houses in the neighbourhood, they never visit each other's homes.

Their conversations often remain superficial. It is therefore always polite to respond positively to the question 'Everything OK'? As Tiny points out (85): 'What should I talk about then? My family? Well, no! That is not my neighbours' business.' If a topic of conversation deals with a shared problem or frustration concerning the supply of goods at the supermarket or the construction works in the neighbourhood, it is easier to express one's discontent. Natives tend to refrain from talking about conflicts involving other residents, even when they have witnessed the conflict and have their own opinion about it. Moreover, a resident who faces problems with another resident rarely garners support.

Although residents report that they do not converse with strangers, observations show that they do indeed make contact at the tram stop, market, snack bar, terrace, pub, and on the streets. Nonetheless, it is still more common to regularly engage in conversation with people they know or recognise from their apartment block or street. Most natives, however, report that they do not have strong ties with native neighbours. As Elles (79) reports:
'I know them, and when I pass their house sometimes I wave. Sometimes, some chitchat occurs, but we do not visit each other. I am not in need of it and think that that is mutual. Or it has to be a coincidence that you have to bring or collect something and the coffee has just been made. Then we will maybe share a cup of cof- fee. But that has been such a long time ago that I do not remember the last time that we did so. People don't expect it. Neighbours should not constantly knock on each other's door, you see.'

In the past, residents were more accustomed to visiting each other at home or sharing a drink in the front garden. Nowadays most resident do not consider paying each other visits as part of a neighbourly relationship. Even when natives do not visit another, they prefer to have native neighbours.

Contact between youngsters is often superficial, such as between Billy (21) and Bobby (22). Although they hang out with each other, know each other well and look alike, they would not consider themselves to be friends. They refrain from using the word friendship, because they expect that there is always some risk of being betrayed. This risk is 
greater with a friend. Although both have a lot of acquaintances in the neighbourhood, they stressed that they did not have friends there and did not visit the homes of other neighbourhood residents. Students living in the neighbourhood have a student-like lifestyle, which is mainly lived outside the neighbourhood.

Although most natives refrain from establishing strong ties in the neighbourhood, exceptions can be found. Middleaged natives enjoy close contact with relatives living in the neighbourhood. They often sit together with a large group of relatives, drinking beer on the street, and are noisy. They are aware of the stigma of being anti-social, but none of the natives interviewed labelled themselves as being disorderly, even when other residents do so. Wim (52):

'Look, we are friends of Hannah and Gerrie (the Tokkies), who are called disorderly. Listen, I know them and they are completely honest people, really. In fact, we are the most social folk in the neighbourhood.'

Another group of disorderly encompasses caravan dwellers, who live in a small tight community of seven caravans. In the evening, all of the groceries are put in the fridge of one caravan one day and then in another on the next, since they often eat and drink together. Although these 'caravanners' distinguish themselves from the anti-social residents on the other side of the road, others do not make that distinction.

Although natives generally do not visit each other, mutual help is often extended, such as lending tools and helping with odd jobs around the house or garden. Obtaining such help is appreciated, but asking for help is viewed as difficult. Lending small items or performing minor tasks is easy, but when a native requires personal care or even care for their animals, other native residents are often not asked. Native residents tend to first ask friends or family living in or outside the neighbourhood.

Generally, mutual assistance, with the exception of odd jobs and lending out small items, is not seen as part of the relationship between neighbours. Nonetheless, differences in attitude can still be discerned among residents. Those with strong ties to relatives in the neighbourhood, such as the group of disorderly residents, make greater use of mutual help and support. For example, the caravanners take care of the dogs and gardens of other dwellers. Here, mutual help and support is more self-evident and widespread, which makes crossing the threshold to ask for assistance far easier.

In sum, natives tend to seek different kinds of contacts with their neighbours. They consider contact with natives living in the same street and housing block important. Natives, who regularly encounter each other in public spaces, make eye contact and greet one another. When they encounter unfamiliar natives, they must decide whether or not to greet them. Although many natives tend to refrain from initiating contact with strangers, some residents will be prepared to establish contact with them.

Natives who know each other converse about superficial matters and generally consider it 'not done' to discuss personal issues. Closer contacts between natives, which go hand in hand with regular visits, are exceptional. On the level of mutual assistance, superficiality also is the rule rather than the exception.

In terms of the characteristics of contacts with other residents, different types can be distinguished. Firstly, there are the encapsulated $(\mathrm{n}=8)$, who belong to networks characterised by strong ties and very warm contacts encompassing greeting, small talks, mutual assistance and sometimes paying a visit to each other. This group includes relatives, but also students who are living in the neighbourhood temporarily. Another example of the encapsulated are the so-called anti-social families who have lived in the neighbourhood for a long period of time. Many interviewed residents label them as noisy, quarrelsome and heavy drinking. Such people do not think of themselves as being anti-social, but are wellaware that others label them as such. The caravanners experience the same stigma. They feel that they are somehow linked with the other disorderly people. The contacts of the encapsulated in the neighbourhood are mainly oriented toward the local network in which they are encapsulated and maintain tight contact. The encapsulated regularly employ mutual assistance with regard to superficial and personal matters. Compared to the other types, the encapsulated have the strongest ties.

Secondly, the integrated $(n=6)$ have a mixed network. They know their neighbours and have superficial contact, encompassing greeting and sometimes a chat. They do not consider themselves to be part of or linked with a specific group of residents. They behave towards all neighbours in the same way by greeting and chatting with them. Integrated natives mainly have acquaintances in the neighbourhood.

Thirdly, the isolated encompass neighbours $(n=2)$ with a very small network. These residents have very superficial contacts, mainly restricted to greeting, with native neighbourhood residents or even with those outside the neighbourhood. It is mainly restricted to greetings, which renders their contact very superficial. Such isolation among these natives, temporary as well as long-standing, is a free choice, or so these interviewees claim.

Fourthly, core residents $(n=6)$ mainly comprise the native elderly who have lived in the neighbourhood for a long time, some even since 1952 when the neighbourhood was first built. They have borne witness to many changes in the neighbourhood and have a very homogeneous network. The core residents maintain a certain distance from each other. They do not form a tight-knit group. Only in exceptional cases do they maintain close contact and consider themselves to be 'better' than their neighbours. Although the core residents share a history of living together in the neighbourhood, intimate ties are not considered to be part and parcel of a neighbourly relationship and are thus avoided as far as possible. If core residents are active in the neighbourhood, they work together with other core residents. These core residents rarely visit other residents, but are prepared to help them with minor tasks. Their contacts were originally very warm, encompassing greeting, chatter, mutual assistance and sometimes paying a visit to each other. Later on, the contact became superficial: restricted to greeting and sometimes a chat. However, in exceptional cases the mutual assistance was also employed, which made the contact warm. 


\section{INTRA-ETHNIC CONTACTS OF TURKISH MI- GRANTS}

Contacts in the neighbourhood between Turks mainly take place in the public space, where Turks meet other Turks living in the same housing block, street and surrounding streets. The first kind of contact is eye contact, which goes hand in hand with recognition of the other. Strangers do not often make eye contact and do not greet each other. The underlying factors are a bit more complex when it comes to strangers. Merve (49), who has lived in the Netherlands for 27 years, says that it is 'not acceptable' to look an unfamiliar man in the eyes. That is why she always lowers hers when she passes strange men. Moreover, she is afraid of the reaction. The stranger may tell other people if she makes eye contact, which could potentially harm her reputation.

Greeting takes place in Arabic by saying 'Salaam Aleikum' or 'Merhaba' in Turkish. If a stranger is greeted, it is done with less enthusiasm than one would with someone who is known. Men who greet other men regularly shake hands, and women embrace other women. With regard to greeting people they know, some Turks still have their own thoughts when it comes to the opposite sex. Mehmet (50) says: 'When I meet a Turkish woman whom I know, I will greet her, but I will not look too much. Thus I will greet her, but not too enthusiastically.' There are significant differences in the extent to which one will approach somebody of the opposite sex. Turkish residents who only know a few neighbourhood residents and are somehow isolated, or residents encapsulated in a tight Turkish (family) network, are more cautious in approaching members of the opposite sex. In general, they hold 'traditional' views on gender relations. Turks born in the Netherlands or who have lived there for a longer period of time commonly hold a more modern view. Turks chat mainly with people they know; here again, sex and honour play an important role. This means that people tend to refrain from making conversation with someone of the opposite sex, even if they are known to them.

Turkish residents often chat in Turkish. Such conversation is often initiated by exchanging polite phrases: 'Everything OK? Good!' Or in Turkish 'Nasselsen?', which will be answered with 'Şok Şükür' or 'Elhamdulillah'. This will be followed by questions: How are you? How are your father and mother? When a youngster speaks to an elderly person, he or she will ask about the youngster's parents. In response, the younger person will inquire about the older person's family. Turks who do not know each other and talk for the first time with each other, such as new neighbours or somebody in the coffeehouse, always ask: 'What is your name? Where do you come from?'

Women encounter each other at the street, supermarket or school playground. Moreover, they meet other Turks at the Dutch or Turkish language classes, but they do not visit each other's homes. While meeting in the street, they tend to make small talk. Some women meet other Turkish residents at multicultural women's parties. At such events homemade food is shared, and dancing takes place, as well as political discussions about the neighbourhood between politicians and neighbourhood residents. Turkish men not only meet each other at the mosque (outside the neighbourhood), but also the Turkish neighbourhood centres and coffeehouses (Kawe). In such meeting places, they watch football, or play cards and
Rummikub. Not all Turks consider meeting in the Kawe to be a good idea, because it conflicts with spending time with their children and wife.

Turkish residents without a shared background of being relatives or coming from the same region in Turkey seldom visit each other. They consider themselves strangers. If Turks have good contact with Turkish residents, because they share their place of origin in Turkey, their mutual ties and trust enable contact. If this basic condition is met, contact can develop and result in regular visits. Then women make snacks, eat together, and talk. Many Turks miss such old acquaintances in their neighbourhood.

Relatives and Turks, who do not come from the same region of origin, rarely enjoy close ties due to distrust and fear of gossip. Gossip and honour play an important role in conversation among Turks. Turks easily feel ashamed, especially when cleanliness and honesty are lacking. The fear of gossip is great, because gossip can damage one's honour, possibly resulting in isolation from the Turkish community. That is primarily why Turks are cautious about establishing friendly relations with neighbours they do not know. Turks will not approach other Turks over undesirable behaviour, because they try to avoid damaging one's honour by minimising the chance of gossip.

The region of origin is also important to the development of reciprocal ties between Turkish residents; this has consequences for reciprocal relationships. Reciprocity often forms the basis for trust among Turks. If you help someone, you can ask them for help if need be. There are, for example, rituals that have to be followed when a Turkish person dies. Women from the street or neighbourhood bring plates of food to the house of the deceased, where they will cry together with the widow.

There is a great deal of intergenerational solidarity among Turks, and the elderly are often offered help, for example, carrying shopping bags. Intergenerational solidarity keeps parents in the household. Elderly interviewees do not prefer nursing homes at all.

In sum, Turkish residents from the same street or housing block generally recognise each other. If Turks meet they enquire after each other's well-being and that of their relatives. It is not self-evident to greet strangers. In the 'traditional' Turkish culture, men and women distance themselves from each other; gossip and family honour are of the utmost importance.

If ties become tighter, such as by paying a visit to one another, the fear of damaging one's reputation plays an important role. What will happen if the contact does not go well or if the visitor thinks that the house is not clean enough? Due to this fear of gossip, Turkish residents who do not know each other well will often maintain a certain distance. A shared background is thus of crucial importance for developing trustful and reciprocal relationships.

The Turkish residents who were interviewed can be divided in different groups: the encapsulated, integrated, isolated and pioneers. Firstly, the encapsulated $(n=6)$ can be found among relatives or members of Turkish-oriented networks having few contacts with non-group residents. Their own network appears to be sufficient. Mutual assistance is 
widespread among these Turks. Moreover, there is a large network of encapsulated Turks, which comprises of Turks from inside and outside the neighbourhood. These Turks share the same region of origin in Turkey. The encapsulated employ 'traditional' gender practices, such as lowering one's eyes, avoiding eye contact between the sexes and having women spend a lot of time inside their house. In short, their contact can be seen as very warm, encompassing greeting, chatter, mutual assistance and sometimes a visit.

Secondly, the integrated Turks $(\mathrm{n}=5)$, such as those of the second generation migrants or individuals who have lived in the Netherlands for a long time, have a mixed network of relatives in the neighbourhood and Turkish friends, some of whom they might know through their parents. In comparison to the encapsulated, they enjoy easier contacts with Turks from other regions of origin. Moreover, the integrated adhere to more modern gender norms and values. They greet anyone they want. Although the integrated do not stick to very 'traditional' norms, they may still take them into account when approaching others. This will be done as a sign of respect to those who do hold more 'traditional' values and norms, such as relatives or parents. Their contact in the neighbourhood can be called superficial, characterised by greeting, and sometimes a chat. Sometimes they have one or two friends with whom the contact is very warm.

Turks who only know each other from their current neighbourhood and who do not share the same region of origin lack the strong bonds of the encapsulated. They are more isolated and, unlike the isolated Dutch residents, this is not a matter of free choice. Isolated Turks $(n=3)$, the third group, include newcomers such as wedding migrants who do not know other residents in the neighbourhood. If they have any neighbourly contact, it is very superficial: restricted to greeting only. The isolated hold 'traditional' values, which results in women staying inside their homes.

Fourthly, pioneers are the first Turks to have moved into a neighbourhood. At time of arrival they were dependent on the natives, because the number of Turks in the neighbourhood was very low. Only one pioneer was interviewed in this research. This woman has a more modern view of contacts between men and women than the encapsulated and isolated. For example, the Turkish pioneer greets many strangers, men and women, which is not common in the 'traditional' Turkish culture. The pioneer considers this to be a means of adaptation to Dutch culture, and it vexes those who still embrace 'traditional' Turkish norms and values. The fear of gossip is almost absent, because the pioneer feels herself to be more like an individual in the neighbourhood. The pioneer is not dependent on contacts with Turks only. This makes it easier to establish contact with other residents and develop tight bonds. It also makes it easier to confront Turkish neighbours about undesirable behaviour. The pioneers had warm contact with multiple other Turks characterised by greeting, making conversation and sometimes paying a visit.

\section{INTERETHNIC CONTACT BETWEEN NATIVE AND TURKISH NEIGHBOURS}

Interethnic eye contact tends to lead to misunderstandings more frequently than intra-ethnic eye contact. Some natives complain about eye contact with Turkish residents. For example, Bas (77) remarks that young Turkish girls in particular can look at you with daggers: 'I find this scary. They can look at you full of hate.' Although eye contact can be experienced as threatening, the lack of eye contact is often seen as an obstacle to further contact. According to many natives, Turkish women often lower their eyes. Many natives view this avoidance of eye contact negatively and do not understand it. Some natives have a different view on such Turkish habits. Billy (21) and Bobby (22) say that they greet everybody on the streets, natives as well as migrants; they do not make any distinction. At that moment, two young Turkish girls wearing headscarves pass, and the two natives fail to greet them. When both boys are confronted with this inconsistency, they reply:

\begin{abstract}
'Yes, such girls mostly look to the ground. They do not say anything and act as though they do not see you. (...) We respect this. Most girls in this neighbourhood are sluts. Dutch girls are sluts. If you meet them they only want one thing, if you know what I mean. This only causes trouble with their boyfriends, with our girlfriends, all trouble. Look, like I'm talking to you right now, just normal talk-that never happens with these girls. And these foreign girls are just being judicious and don't provoke anything nasty.'
\end{abstract}

Turks and natives consider it important to know people in the neighbourhood. Recognising residents from the same flat or in the street encourages the exchange of greetings, but when residents are unknown a greeting does not always take place. According to Truda (55), unfamiliar Turkish men do not greet her, but unfamiliar Turkish women do. Many of the Turks who were interviewed do not 'concur', stating that Turks who think that women should lower their eyes often make an exception for natives. Turks will greet natives more often than a Turk of the opposite sex.

Turks, although less so than natives, stress that the greeting behaviour of natives is disturbing and confusing. For example, Ermine (39) says that she gets the impression that native women will especially ignore her. However, other interviewed Turks do not complain about the greeting behaviour of the natives. Some Turks even greet more natives on the street than Turks. Marie (79), who always greets Turkish youngsters on the street, says: 'If you greet them normally and respect them, than you can expect that your greeting will be reciprocated.' Although Turks and natives recognise and greet each other, they engage in less conversation due to the language gap. For example, natives express their discontent that they cannot communicate with their Turkish neighbours, making it 'no fun' to deal with them. That is why many natives prefer having natives as neighbours.

Furthermore, many Turks feel that it is a shame that they cannot chat with their native neighbours. Although many do not speak Dutch fluently, they are able to engage in superficial banter. Those taking language classes often fear that they master Dutch insufficiently. Moreover, it is assumed that Turkish women will take care of the household, which strengthens their home-boundedness and limited knowledge of Dutch. Both hinder contact between Turkish women and natives. The fear of damaging one's honour leads some 'traditional' households to keep their daughters behind closed doors. Most interviewed Turks stress that such practices are 
on the decline. The second generation is more modern, speaks better Dutch and will talk more often with native neighbours. Apart from the language gap, the 'blackness' of the school - expressing the percentage of schoolchildren from non-Western origin - and the design of the apartment blocks and flats also hinder the development of interethnic contacts.

Although several Turks claim that they chose to live in the neighbourhood because of the large number of Turks there, many Turks today prefer to have more Dutch neighbours, which may help them to master the Dutch language. Natives, however, will rather have no or only a few Turkish neighbours, because they do not like not being able to make conversation.

Greetings are often exchanged between Turkish and native neighbours, but conversation is less frequent. Only in rare cases do they visit each other's homes. Native core residents often blame the Turks for their mutually weak ties. Natives try to contact Turks coming to the neighbourhood, but they are not successful and give up.

In some cases, Turks join resident associations, but the frustration of the natives is that they do not keep their promises. The natives refer to the Turkish culture and the division between the sexes as an obstacle to making appointments. Nowadays, the native participatory elites do not engage in many or often even any efforts to build a heterogeneous network. This elite encompasses mainly middle-aged nativeborn Dutch people.

Truda (55) stresses that the lack of contact between Turks and natives is the Turks' fault. She had invited neighbourhood children, but her son was never invited to a Turkish birthday party, where mainly Turkish children and relatives gather. Turks confirm that birthday parties, like the ones thrown by natives, are not that common among Turks. Whereas native children will invite a group of children from the school class or neighbourhood to their birthday party, Turkish children tend to celebrate their birthdays with their family only. If neighbours are invited, it will more often be adults, such as a native elderly person, rather than a neighbour's child.

Close contacts between peers of the same age are rare among Turks and native residents, but they may occur with elderly natives. Turks often take the initiative in establishing and maintaining such contact. Aged native neighbours are often called 'grandma' or 'grandpa', and they are invited to children's birthday parties. However, language remains a barrier, especially when Turkish is the main language spoken at such parties. Meryem (20) said that her 'grandma' Bep is always welcome, but that Bep keeps her distance.

There is rarely warm contact between younger natives and Turks. Turkish youngsters (at least those who are integrated) enjoy more contacts outside the Turkish community. They have greater interaction with natives through schools, jobs or clubs and rarely have close contacts in the neighbourhood.

In particular, Turks born in the Netherlands have more acquaintances outside their own ethnic group, but they still have few native friends. The question of trust is of great importance here. For example, Ufuk (43) says that he visits a local native pub regularly. There he has contact with natives as well as migrants, but his friends are Turkish, because he trusts Turks more.

Turkish youngsters identify with the hospitality and respect of the Turkish culture. Turks help native elderly people more often than the other way around. Sometimes such care could even prevent someone having to move to a nursing home. Turks regularly help native as well as Turkish elderly carry their shopping bags, especially when they know each other from the apartment block where they encounter each other and exchange greetings. However, not all Turks will help their neighbours. When a new Turkish family enters the neighbourhood, natives often help with the installation of equipment, household repairs, lending tools, pushing stalled cars, and so on. Turks give food or snacks in return.

Natives may help Turks to obtain social security benefits or the assistance of a Dutch institution. A lot of help will be offered without asking. For example, shopping bags are taken over spontaneously, and new neighbours are asked whether they need help. When the natives go on holiday, they do not approach their Turkish neighbours with respect to taking care of their plants or animals. They prefer to ask friends and want to keep a certain distance from others. Turkish neighbours also often refrain from asking for the help of native neighbours during holidays. If necessary, they tend to ask relatives in the neighbourhood or Turkish acquaintances. However, it still is appreciated when native neighbours keep an eye on their house when they are away. This means that they find solutions intra-ethnically and not interethnically.

Natives often complain about the Turks' untidiness in public space, such as dumping rubbish and litter on the street at all hours, but also other nuisances, such as playing car radios too loudly and using mobile phones in the evening and night on the streets. Along with complaints about lack of lawn and garden maintenance, other natives refer to shoes left in stairwells and buggies parked in the entrance halls of apartment blocks. A common staircase encourages contact between people who share the same entry door, but conflicts may also occur when rubbish bags leak and the floor is not cleaned. Natives stress that they do not want too many Turkish neighbours on their street. In addition to the language barriers, the neighbourhood would look impoverished and uninviting if too many non-Western migrants settled there.

Turks, especially the integrated and the pioneers, like to have native neighbours. The appearance of the neighbourhood is also of great importance to these Turks. When houses are renovated and pulled down, the disarray on the street increases. People have to move out temporarily and empty their apartments. Furniture that is not going to be moved into their new homes is simply dumped on the street. Too many pigeons are attracted by food thrown on pavements and into the gutters. There is a lot of rubbish and destruction in the playgrounds. Turks and natives blame Moroccans for causing these problems. Although natives tend to lump Turks and Moroccans together, Moroccans are generally viewed far more negatively than Turks.

Neighbours do not always approach each other about their disruptive behaviour, but when they do, they sometimes are successful. Bets (65), for example, asked her Turkish 
neighbours to refrain from grilling food outside every day because of the smoke. This intervention helped: they limited their barbequing and, when they do, they now bring a plate of food round to her. Solutions are more difficult to achieve when it comes to complaints about the public space. Natives stress that Turks react indifferently to requests to keep the neighbourhood neat and tidy. There is a lack of a collective feeling of responsibility.

For Turkish residents of all types, the Islamic religion is an important part of their identity. However, 9-11 has changed the way that they experience Islam. Natives stress the religious identity of non-Western migrants and Turks feel that they are seen first and foremost as Muslims. Due to critical questions and the prejudices of the natives, integrated Turks find themselves wanting to know more about Islam in order to defend themselves. Some interviewed natives suggest that Islam has gained importance, a trend that is associated with the increased number of headscarves on the street.

Although Turks do not consider their religion as a stumbling block to interethnic contact, the contemporary negative image of Muslims creates a fissure between them and natives. The latter, more than Turks, consider Islamic identity to be a stumbling block in secular Dutch society. Islam may indeed widen the gap between Turks and natives. The natives Billy (21) and Bobby (22) have become interested in Islam and consider it a 'better' religion than Christianity; they argue that the Koran is more pure and tells the real story. They also praise 'traditional' Turks with respect to the (non-)interaction between both sexes.

Natives and Turks know little about each other's cultures and often lack the desire to learn more about the other group. Several natives reacted furiously to the question whether they would like to better understand the Turkish culture. For example, Kees (49) argues: 'Turks haven't adapted at all, and this is all accepted. And now we are supposed to learn about their culture. Let it be the other way around.' The natives' lack of awareness of the Turkish neighbours' culture leads to prejudices. Turks and Moroccans are often confused with each other. Many of the prejudices of natives concern Turkish women, who are believed to be severely suppressed and not allowed to talk to anybody. Domestic violence is believed to be widespread. Bets (65), for example, said the following about Turkish women: 'In their culture Daddy is the boss, who can impose his will.' The wearing of headscarves is also often not understood by natives.

The lack of native's knowledge can lead to negative remarks about Turks. Turks are often seen as profiteers in Dutch society, including profiting from social security benefits that supposedly enable them to build houses in Turkey. A commonly expressed frustration of natives about Turks is that they spend the best part of the year in their houses in Turkey but still occupy large apartments in the Dutch neighbourhood. This is considered unfair to those on the long social housing waiting list, who are waiting to obtain a (better) house.

Likewise, natives believe that Turks living in the Netherlands are different to Turks in Turkey, who would also feel ashamed of the criminal and passive behaviour of Turks in the Netherlands. Although these views were often vented, some natives defended and helped the Turks. Marie (79) is more negative about Turks in general than about the Turkish women who live in her apartment building. Views on unemployment and alleged abuse of the Dutch welfare state are often more nuanced when known Turks are concerned. If Turks, even acquaintances, are successful, they will be experienced as a threat: 'many jobs already have been taken by migrants.' The Turkish interviewees also note that many native residents label the Turks negatively. As Ufuk (43) observes: 'When I arrived in the Netherlands in 1978, everybody was very friendly. Nowadays, everybody has changed, also the Turks.'

\section{INTRA- AND INTERETHNIC CONTACTS RECON- SIDERED}

Before looking into the interethnic contacts between natives and Turks, we will focus on the intra-ethnic contact of both ethnic groups. At first sight, the classification of the intra-ethnic contacts of native and Turkish neighbourhood residents appear to be largely similar (see for an overview Table 3), However, when one looks in more detail dissimilarities appear.

Although natives consider contact with other natives living in the same street and housing block important, they employ different kinds of contacts with neighbours. Natives, who regularly encounter each other in public spaces such as the street, make eye contact and greet one another. When they bump into unfamiliar natives, they have to make up their mind whether or not to greet them. Although many native-born tend to refrain from initiating contact with strangers, some are prepared to establish contact. Natives who know each other talk about superficial matters and generally consider it inappropriate to discuss personal issues. More intimate contacts between natives, which go together with regular visits, are rare. On the level of mutual assistance, superficiality is common. Moreover, those with strong ties to relatives in the neighbourhood employ more mutual help.

Turks from the same street or housing block generally recognise each other when they meet in public spaces. If Turkish residents meet they ask after each other's well-being and that of their relatives. It is, however, not considered appropriate to greet strangers. In the 'traditional' Turkish culture, both sexes distance themselves from each other. Moreover, gossip and family honour play a very important role. If ties become more extensive, such as by paying a visit to one another, the fear of damaging one's reputation plays an important role. Due to the fear of gossip, Turkish residents who do not know each other well will often maintain some distance. It appears that a shared background - a common region of origin, for instance - is crucially important for developing trustful and reciprocal relationships.

In general, the ties between Turks appear to be closer than among natives. This indicates that encapsulated residents and pioneers tend to dominate the general picture sketched above. However, we have to take into account that the size of the different neighbourhood networks among natives as well as Turks is not known. With the similarities and differences concerning intra-ethnic contacts of natives and Turks in mind, we can look into the nature of interethnic contacts. Here, ethnic differences colour the dynamics of contact. 
Table 3. Intra-Ethnic Contacts of Native and Turkish Neighbourhood Residents

\begin{tabular}{|c|c|c|}
\hline & Natives & Turks \\
\hline \hline Encapsulated residents & Very warm & Very warm \\
\hline Integrated residents & Superficial & Superficial \\
\hline Isolated residents & Very superficial & Very superficial \\
\hline $\begin{array}{c}\text { Core residents (Natives) } \\
\text { Pioneers (Turks) }\end{array}$ & Superficial & Warm \\
\hline
\end{tabular}

Very superficial contact: only greeting on street.

Superficial contact: greeting and sometimes a chat

Warm contact: greeting, rarely a chat, mutual assistance.

Very warm contact: greeting, chatter, mutual assistance, sometimes visit.

Concerning interethnic contact, all interviewed natives agree that Turks and natives should greet each other. Although some natives get annoyed when Turkish residents do not greet them, Turks stress that gender does not influence the interethnic greeting behaviour between Turks and natives. Although encapsulated and isolated Turks share the view that contact between men and women has to be avoided as much as possible, they make an exception for (elder) natives. Although Turks and natives often greet one another, conversation rarely ensues unless the Turkish neighbour has mastered the Dutch language. Together with linguistic problems, other obstacles for contact include patriarchal values concerning men and women, which restrict women's appearance in public space.

Turks who master Dutch well and have been settled in the Netherlands for a long time or have even grown up there, like the Turkish pioneers and integrated, converse with native neighbours more frequently. A precondition is that natives live nearby or in the same apartment block. If mastery of Dutch is not a problem, all types of native residents are willing to engage in conversation.

Turkish residents appreciate native neighbours and want to have contact with them. Natives, especially core residents, do not like having Turkish residents, because they cannot talk with them, which is considered very awkward. Native core residents said that they often indicated that they were more open to contact, but they have not been successful in initiating contact with Turkish neighbours. Sentiments like 'they had their chance and now they're too late taking it' were often expressed by natives.

Not all interethnic contacts are superficial. Warm contacts are also particularly prevalent between Turks and elderly native core residents Turks generally assume that the elderly should be treated with respect and care, and therefore they extend their help to elderly natives. Only the isolated Turks refrain from offering such help, because they do not know natives in the neighbourhood or have not mastered the Dutch language.

Different types of Turkish residents spontaneously offer different kinds of help, such as carrying shopping bags. However, sometimes it goes much further: for example, a Turkish pioneer took care of and nursed her elderly neighbour until she died. Core native residents do not prefer to approach neighbours to ask for help, such as taking care of the house, plants, animals or elderly relatives. They prefer to ask their relatives or friends for help. A native neighbour may take care of the plants and pets, but a key will not be easily given to the Turkish neighbours.

Natives sometimes help their Turkish neighbours with small tasks, but the intergenerational support of Turkish households towards elderly native (core) residents dominates. The encapsulated natives of the anti-social section in the neighbourhood do regularly help their Turkish neighbours. The Turks who are helped, with for example, connecting electrical equipment give their neighbours homemade food in return. This reciprocal relationship mainly exists among encapsulated natives and 'traditional', encapsulated and isolated Turkish neighbours.

Children of pioneer and integrated Turks often approach native core residents by calling them 'grandmother' or 'grandfather'. These natives will also be invited to their birthday parties. Even when such contacts exist, language can still present a barrier to establishing and maintaining the contact. If Turkish adults only speak Turkish, the native feels uneasy or irritated and tends to withdraw.

Although many Turkish neighbourhood residents want to have closer contact with native neighbours, natives often keep them at a distance. Core residents do not consider neighbourhood bonds with natives and Turks as personal relationships.

Native and Turkish integrated neighbourhood residents stress that they like to have more contact with members of the other ethnic group. In reality, this does not happen. In the Turkish and native neighbourhood networks members of the other ethnic group are absent, mostly due to a lack of mutual trust.

An overview of the different types of interethnic contact is presented in Table 4. All types of Turkish and native neighbourhood residents are ideal-types. Besides the characteristics that have been discussed, exceptions can be found when spontaneous encounters occur or when there are individual differences within the types, such as with respect to the extent of Dutch language abilities.

All of the native respondents share many prejudices about Turks. Such prejudices and even fear among natives is related to the Islamic background of Turkish neighbourhood residents. Natives only slightly understand Turkish Muslims, and they talk of being afraid that Turks will take over the neighbourhood or change it into an Islamic neighbourhood. Natives express fewer prejudices about the Turkish residents they know personally. These Turks are seen as being different from other Turks.

All of the Turks interviewed were aware of these prejudices. Some stress their Turkish background even when they have been living in the neighbourhood for a long time. In particular, the encapsulated are focused entirely on their own group and their country of origin. The encapsulated express their discontent about Dutch society and their feelings of not belonging. In a way natives see and threaten them as Turks, which strengthens their Turkish identity.

The integrated Turks face difficulties in finding out which group they belong to. Some consider themselves to be more Dutch, while others feel that they are as much Turkish as Dutch. The pioneer stresses that she does not like to be 
Table 4. Interethnic Contacts Between Natives and Turks Neighbourhood Residents

\begin{tabular}{|c|c|c|c|c|c|}
\hline \multirow{6}{*}{ 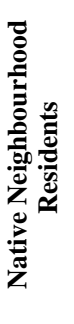 } & & \multicolumn{4}{|c|}{ Turkish Neighbourhood Residents } \\
\hline & & Encapsulated & Integrated & Isolated & Pioneer \\
\hline & Encapsulated & Warm** & Superficial & Warm** & Superficial \\
\hline & Integrated & Very superficial & Superficial & Very superficial & Superficial \\
\hline & Isolated & Very superficial & Very superficial & Very superficial & Very superficial \\
\hline & Core residents & Warm* & Very warm* & Very superficial & Very warm* \\
\hline
\end{tabular}

Very superficial contact: only greeting on street.

Superficial contact: greeting and sometimes a chat.

Warm contact: greeting, rarely a chat, mutual assistance.

Very warm contact: greeting, chatter, mutual assistance, sometimes visit

*Initiative comes from Turkish resident.

***nitiative comes from native resident.

seen as being Turkish due to the negative image of Turks, which has developed among natives.

All of the Turkish interviewees were Muslims and consider this religious identity important. Natives often stress that many Turkish residents have become more religious, but these Turks deny it. In the past, they were approached as Turks; now they are seem as Muslims when it comes to harsh judgements being passed. Some Turks have responded to this change by becoming more interested in their religion, which offers them the opportunity to defend themselves against the critical remarks of natives.

Turkish neighbourhood residents consider their religious or ethnic differences to be a stumbling block to establishing interethnic contact to a lesser extent than natives. The biggest obstacle mentioned by Turks is the native's ignorance of and prejudices against the Turkish culture and Islam. The commonly used expression that 'everybody has lived in his mother's womb for nine months' signifies a belief that differences between groups are irrelevant and that all people are equal.

\section{CONCLUSIONS}

Although many contacts between different categories of residents are superficial or very superficial, interaction is generally also spontaneous, affectionate and friendly. Moreover, the interethnic contact between native and Turkish neighbourhood residents demonstrates that there is not one pattern; different types of interethnic contact can be distinguished within and between both ethnic groups. Native and Turkish residents are identified as isolated, integrated and encapsulated residents. Moreover, among natives and Turks one can also categorise core residents and pioneers respectively. In other words, the different networks are characterised by specific social identities and types of contact employed.

In the neighbourhoods researched, positive contacts between native and Turkish residents predominate, but the fact that there are frictions between specific native and Turkish networks and their own social identities should not be ignored. Many native interviewees express their grievances about Turks and Muslims in general and experience competition with them in a neighbourhood with a majority of nonwestern migrants. Turks are subject to many prejudices, such as taking over housing and the neighbourhood, profiting from the welfare state, and 'stealing' specific jobs.
The stigmatisation of another ethnic group asks for adjustments of the outsider- established configuration of Elias and Scotson. In neighbourhoods 4 and 5 it is not only the interaction between newcomers and established residents, which determine the status quo. It is also determined by the dominant public and political discourse, which equates Muslims with suspicion of terrorism or fundamentalism. In other words, a neighbourhood cannot be studied as an isolated space. The broader context has to be included.

Despite stigmatisation in Slotermeer, natives do enjoy positive contacts with Turkish neighbours, but these familiar Turks are often seen as an exception to the rule. Here contact improves the view of the other, but it does not reduce prejudices linked to Turkish migrants in general. This is also confirmed by Bovenkerk et al.'s findings on how the contact hypothesis works in a multicultural environment. Moreover, natives' negative experiences can influence contacts with Turks. In particular, native core residents stress that they have invested a lot in Turkish migrants in the past. They do not want this to continue and spread many prejudices about them. However, these prejudices often do not coincide with their daily experiences, which suggest that the Turks they know are rather different.

Turkish residents are aware of these prejudices. Reactions are manifold among the different types. Encapsulated Turks contend that the prejudices encourage a stronger orientation toward Turks in the neighbourhood and Turkey, because natives do not treat them equally. Integrated Turks stress that they have a Turkish and a Dutch identity. The Turkish pioneer tries to convince the natives that she is different by behaving in as modern and independent a way as possible and by adjusting more to native customs.

In order to be able to answer critical questions and to counter prejudices from natives, Turks from all categories say that they feel under pressure to know more about Islam. Islam is always important to the Turks, but the natives generally stress that the Islamic identity has increased. None of the Turkish respondents reported that they had started labelling the irreligious more negatively. They would prefer for the natives to stop stigmatising the Turks and to instead adopt a more open attitude towards Islam.

Native residents of all categories hold prejudices against Turks and Muslims and consider themselves to be better than Muslims, who are believed to have strange ideas and employ 
barbarian practises. The native interviewees, with the exception of some integrated natives, are not really interested in obtaining more knowledge about Islamic practises, nor whether their fear of Muslims is justified. Most natives stress the differences with the Turks, but Turks themselves do not.

Our findings show that the interethnic contacts between natives and Turks are more dynamic and diverse than assumed in the integration debate. Better understanding encounters between ethnic groups can provide insight into patterns of interaction and judgements of other ethnic groups. Insight in this interaction is essential to create a steppingstone towards 'integration' in Dutch society.

This study has provided new insights, but also new questions arose. The available data did not allow us to make an in-depth comparison according to age end gender, and being a newcomer or not. Moreover, it is not clear whether there is a neighbourhood effect and which types of contacts are more widespread among specific ethnic groups. This provides food for thought for future research.

\section{ACKNOWLEDGEMENTS}

We would like to thank Patrick Ireland and two anonymous referees for their comments on an earlier version of this paper.

\section{REFERENCES}

[1] Joppke C. The retreat of multiculturalism in the liberal state: Theory and policy. Br J Sociol 2004; 55: 237-57.

[2] Koopmans R, Statham P, Giugni M, Passy F. Contested citizenship: Immigration and cultural diversity in Europe. Minneapolis: University of Minnesota Press 2005.

[3] Scheffer P. Het land van aankomst. Amsterdam: De Bezige Bij 2007.

[4] Sniderman PM, Hagendoorn L. When ways of life collide. Multiculturalism and its discontents in the Netherlands. Princeton: Princeton University Press 2007.

[5] Duyvendak JW, Pels T, Rijkschroeff R. A multicultural paradise? The cultural factor in Dutch integration policy. Paper presented at the $3^{\text {rd }}$ ECPR conference, Budapest. September 8-10, 2005.

[6] Pettigrew TF, Meertens RW. The Verzuiling puzzle: Understanding Dutch intergroup relations. In: Stone J, Dennis R, Eds. Race and Ethnicity: Comparative and theoretical approaches. Oxford etc.: Blackwell 2003; pp. 114-24.

[7] Verkuyten M, Zaremba K. Interethnic relations in a changing political context. Soc Psychol Q 2005; 68: 375-86.

[8] Völker B. 16 miljoen buren: De rol van buren in persoonlijke netwerken in Nederland. Tijdschr Sociol 2000; 21(4): 337-62.

[9] Blokland T. Urban bonds: Social relationships in an inner city neighbourhood. Cambridge: Polity Press 2003.

[10] Tennekes J. Communicatie en Cultuurverschil. M\&O, Tijdschrift voor organisatiekunde en sociaal beleid 1994; 48(2): 130-44.
[11] Dixon JC. The ties that bind and those that don't: Toward reconciling group threat and contact theories of prejudice. Soc Forces 2006; 84(4): 2179-204

[12] Duronto PM, Nishida T, Nakayama S-I. Uncertainty, anxiety, and avoidance in communication with strangers. Int J Intercult Relat 2005; 29(5): 549-60.

[13] Komter AE, Burgers J, Engbersen, G. Het cement van de samenleving: Een verkennende studie naar solidariteit en cohesie. Amsterdam: Amsterdam University Press 2004.

[14] Smets P, Ten Kate S. Let's meet! Let's exchange! LETS as an instrument for linking asylum seekers and the host community in the Netherlands. J Refugee Stud 2008; 21(3): 326-46.

[15] Elias N, Scotson JL. The established and the outsiders: A sociological enquiry into community problems. London: Sage 2001.

[16] Bovenkerk F, Bruin K, Brunt K, Wouters H. Vreemd volk, gemengde gevoelens: Etnische verhoudingen in een grote stad. Amsterdam: Boom 1985.

[17] May D. The struggle of becoming established in a deprived innercity neighbourhood. Nota di Lavoro 101.2003. [Retrieved on June 25, 2008]. Available from: http://papers.ssrn.com/abstract_id= 478423

[18] Miller N, Brewer MB. Groups in contact: The psychology of desegregation. New York: Academic Press 1984.

[19] Verkuyten M. Groepsidentificaties en intergroepsrelaties onder Turkse Nederlanders. Mens Maatschappij 2006; 81(1): 64-84.

[20] Verkuyten M, Yildiz AA. National (dis)identification and ethnic and religious identity: A study among Turkish-Dutch muslims. Personal Soc Psychol Bull 2007; 33(10): 1448-62.

[21] Butter E. Federatie Steunfuncties Minderheden (FSM) 2007. [Retrieved on March 15, 2007]. Available from: http://www.afsm.n1/4 903321/data/turks001.htm

[22] Dagevos J, Gijsberts M, Van Praag C. Rapportage minderheden 2003. Den Haag: Sociaal Cultureel Planbureau 2003.

[23] Roy O. De Islam en de scheiding van kerk en staat. Amsterdam: Van Gennep 2005

[24] Gijsberts M, Dagevos J. Concentratie en wederzijdse beeldvorming tussen autochtonen en allochtonen. Migrantenstudies 2004; 2(3): $145-68$.

[25] Gijsberts M, Dagevos J. Uit elkaars buurt: De invloed van etnische concentratie op integratie en beeldvorming. Den Haag: Sociaal en Cultureel Planbureau 2005.

[26] Van Praag C. Wederzijdse beeldvorming. In: Gijsberts M, van Praag C, Eds. Rapportage minderheden: Onderwijs, arbeid en sociaal-culturele integratie. Den Haag: SCP 2003; pp. 363-92.

[27] Allport GW. The nature of prejudice. Cambridge: Perseus 1979 [1954].

[28] Amir Y. Contact hypothesis in ethnic relations. Psychol Bull 1969; 71(5): 319-42

[29] Van der Oord M, Lindeman E, Slot J. De staat van de wijk. Geuzenveld slotermeer. Amsterdam: Gemeente Amsterdam dienst onderzoek en statistiek 2006

[30] O+S Kerncijfers Amsterdam 2006. [Retrieved on June 12, 2007]. Available from: http://www.os.amsterdam.nl/tabel/8705

[31] Welstand Amsterdam. Map Amsterdam 2006. [Retrieved on July 15, 2008]. Available from: http://www.dedigitaleschoonheid.nl/ws_ php/login.php3

[32] Babbie E. The practise of social research. California: Wadsworth 2004.

[33] Corbin J, Strauss A. Grounded theory research: Procedures, canons, and evaluative criteria. Qual Sociol 1990; 13(1): 3-21. 